Alexandre Faure,

Universite de Rennes (Departament de Droit)/France/

\title{
Public international law controversies over land acquisition and lang grabbing. A socio-legal perspective
}

Paper Presented at the III Regional Conference on Social And Economic Human Rights, San Diego, March 15-16 2015.

\section{Introduction}

The term "land grabbing" is defined as very large-scale land acquisitions, either buying or leasing, in developing countries. The size of the land deal is multiples of 100,000 hectares $(240,000$ acres $)$ and thus much larger than in the past. The term is itself controversial. In 2011, Borras, Hall and others wrote that "the phrase 'global land grab' has become a catch-all to describe and analyze the current trend towards large scale (trans)national commercial land transactions." Ruth Hall wrote elsewhere that the "term 'land grabbing', while effective as activist terminology, obscures vast differences in the legality, structure, and outcomes of commercial land deals and deflects attention from the roles of domestic elites and governments as partners, intermediaries, and beneficiaries". The Overseas Development Institute (ODI) reported in January 2013, that with limited data available in general and existing data associated with NGOs interested in generating media attention in particular, the scale of global land trade may have been exaggerated. They found the figures below provide a variety of estimates, all in the tens of millions of hectares. Most seem to arrive at a ballpark of 20-60 million hectares. Given that total global farmland takes up just over 4 billion hectares, these acquisitions could equate to around 1 per cent of global farmland. However, in practice, land acquired may not have previously been used as farmland, it may be covered by forests, which also equate to about 4 billion hectares worldwide, so transnational land acquisition may have a significant role in ongoing deforestation. The researchers thought that a sizeable number of deals remain questionable in terms of size and whether they have been finalised and implemented. The land database often relies on one or two media sources and may not track whether the investments take place, or whether the full quantity reported takes place. For example, a number of deals in the GRAIN database appear to have stalled including. The researchers claim these are only those that have been checked, and already amount to nearly 10 per cent of the GRAIN database transnational land acquisitions. Deals are reported that use the estimate of the full extent of land that the firm expects to utilise.

\section{Land Value}

The researchers found that in terms of value of transnational land acquisitions, it is even harder to come across figures. Media reports usually just give information on the area and not on the value of the land transaction. Investment estimates, rather than the price of purchase are occasionally given. They found a number of reports in land databases are not acquisitions, but are long-term leases, where a fee is paid or a certain proportion of the produce goes to domestic markets. For example:

- An Indian investment in Ethiopia, where price per hectare ranged from $\$ 1.20$ to $\$ 8$ per hectare per year on 311,000 hectares

- Indian investors paid \$4 per hectare per year on 100,000 hectares.

- Prince Bandar Bin Sultan of Saudi Arabia was reported to be paying \$125,000 per year for 105,000 hectares in South Sudan, less than $\$ 1$ per year on a 25-year lease.

- A South Korean investor in Peru was reported to be paying $\$ 0.80$ per hectare.

The estimated value has been calculated for IFPRI's 2009 data to be 15 to 20 million hectares of farmland in developing countries, worth about $\$ 20$ billion- $\$ 30$ billion. 
Researchers discovered global investment funds are reported to have sizeable funds available for transnational land investments.

- One estimate suggests " $\$ 100$ billion waiting to be invested by 120 investment groups" while already "Saudi Arabia has spent $\$ 800$ million on overseas farms". In 2011, a farm consultancy High Quest told Reuters "Private capital investment in farming in expected to more than double to around \$5-\$7 billion in the next couple of years from an estimated \$2.5$\$ 3$ billion invested in the last couple of years".

There is significant uncertainty around the value of transnational land acquisitions, particularly given leasing arrangements. Given the quantity of land and the size of investment funds operating in the area, it is likely that the value will be in the tens of billions of dollars.

\section{Land destinations}

Researchers used the Land Portal's Land Matrix database of 49 billion hectares of land deals, and found that Asia is a big centre of activity with Indonesia and Malaysia counting for a quarter of international deals by hectares. India contributes a further 10 per cent of land deals. The majority of investment is in the production of palm oil and other biofuels. They determined that the Land Portal also reports investments made by investors within their home country and after stripping these out found only 26 million hectares of transnational land acquisitions which strips out a lot of the Asian investments. The largest destination countries include.

\section{Other deals}

Other estimates of the scope of land acquisition, published in September 2010 by the World Bank, showed that over 46 million ha in large-scale farmland acquisitions or negotiations were announced between October 2008 and August 2009 alone, with two-thirds of demanded land concentrated in Sub-Saharan Africa. Of the World Bank's 464 examined acquisitions, only 203 included land area in their reports, implying that the actual total land covered could more than double the World Bank's reported 46 million ha. The most recent estimate of the scale, based on evidence presented in April 2011 at an international conference convened by the Land Deal Politics Initiative, estimated the area of land deals at over 80 million ha.

Of these deals, the median size is 40,000 ha, with one-quarter over 200,000 ha and one-quarter under 10,000 ha. $37 \%$ of projects deal with food crops, $21 \%$ with cash crops, and $21 \%$ with biofuels. This points to the vast diversity of investors and projects involved with land acquisitions: the land sizes, crop types, and investors involved vary wildly between agreements. Of these projects, $30 \%$ were still in an exploratory stage, with $70 \%$ approved but in varying stages of development. $18 \%$ had not started yet, $30 \%$ were in initial development stages, and $21 \%$ had started farming. The strikingly low proportion of projects that had initiated farming signifies the difficulties inherent in large-scale agricultural production in the developing world.

Investment in land often takes the form of long-term leases, as opposed to outright purchases, of land. These leases often range between 25 and 99 years. Such leases are usually undertaken between national or district governments and investors. Because the majority of land in Africa is categorized as "non-private" as a result of government policies on public land ownership and a lack of active titling, governments own or control most of the land that is available for purchase or lease. Purchases are much less common than leases due to a number of countries' constitutional bans on outhright sales of land foreigners.

The methods surrounding the negotiation, approval, and follow-up of contracts between investors and governments have attracted significant criticism for their opacity and complexity. The negotiation and approval processes have been closed in most cases, with little public disclosure both during and after the finalization of a deal. The approval process, in particular, can be cumbersome: 
It varies from approval by a simple district-level office to approval by multiple national-level government offices and is very subjective and discretionary. In Ethiopia, companies must first obtain an investment license from the central government, identify appropriate land on the district level and negotiate with local leaders, then develop a contract with the regional investment office. Afterwards, the government will undertake a project feasibility study and capital verification process, and finally a lease agreement will be signed and land will be transferred to the investor. In Tanzania, even though the Tanzania Investment Centre facilitates investments, an investor must obtain approval from the TIC, the Ministry of Agriculture, the Ministry of Lands and Housing Development, and the Ministry of Environment, among which communication is oftentimes intermittent.

\section{Target countries}

One common thread among governments has been the theme of development: Target governments tout the benefits of agricultural development, job creation, cash-crop production, and infrastructure provision as drivers towards economic development and eventually modernization. Many companies have promised to build irrigation, roads, and in some cases hospitals and schools to carry out their investment projects. In return for a below-market-rate $\$ 10 /$ ha annual payment for land, Saudi Star promised "to bring clinics, schools, better roads and electricity supplies to Gambella." Governments also count new job creation as a significant feature of land acquisitions.

The issue of agricultural development is a significant driving factor, within the larger umbrella of development, in target governments' agreement to investment by outsiders. The Ethiopian government's acceptance of cash crop-based land acquisitions reflects its belief that switching to cash crop production would be even more beneficial for food security than having local farmers produce crops by themselves. Implicit in the characterization of African agriculture as "underdeveloped" is the rejection of local communities' traditional methods of harvesting as an inadequate form of food production.

On a smaller scale, some deals can be traced to a personal stake in the project or possibly due to corruption or rent-seeking. Given the ad hoc, decentralized, and unorganized approval processes across countries for such transactions, the potential for lapses in governance and openings for corruption are extremely high. In many countries, the World Bank has noted that investors are often better off learning how to navigate the bureaucracies and potentially pay off corrupt officers of governments rather than developing viable, sustainable business plans.

\section{Responses}

Since 2010 Brzail enforces in a stricter way a long-existing law that limits the size of farmland properties foreigners may purchase, having halted a large part of projected foreign land purchases.

In Argentina, as of September 2011, a projected law is discussed in parliament that would restrict the size of land foreign entities can acquire to 1000 hectare.

\section{Types of land investment}

Investors can be generally broken down into three types: agribussines, governments, and speculative investors. Governments and companies in Gulf States have been very prominent along with East Asian companies. Many European- and American-owned investment vehicles and agricultural producers have initiated investments as well. These actors have been motivated by a number of factors, including cheap land, potential for improving agricultural production, and rising food and biofuel prices. Building on these motivations, investments can be broken down into three main categories: food, biofuel, and speculative investment. Forestry also contributes to a significant amount of large-scale land acquisition. 


\section{Food}

Food-driven investments, which comprise roughly $37 \%$ of land investments worldwide, are undertaken primarily by two sets of actors: agribusinesses trying to expand their holdings and react to market incentives, and government-backed investments, especially from the Gulf states, as a result of fears surrounding national food security.

Agricultural sector companies most often view investment in land as an opportunity to leverage their significant monetary resources and market access to take advantage of underused land, diversify their holdings, and vertically integrate their production systems. The World Bank identifies three areas in which multinational companies can leverage economies of scale: access to cheap international rather than domestic financial; markets, risk-reducing diversification of holdings , and greater ability to address infrastructural roadblocks. In the past few decades, multinationals have shied away from direct involvement in relatively unprofitable primary production, instead focusing on inputs and processing and distribution. When the food price crisis hit, risk was transferred from primary production to the price-sensitive processing and distribution fields, and returns became concentrated in primary production. This has incentivized agribusinesses to vertically integrate to reduce supplier risk that has been heightened by the ongoing food price volatility. These companies hold mixed attitudes towards food imports and exports: While some concentrate on food exports, others focus on domestic markets first.

While company-originated investments have originated from a wide range of countries, government-backed investments have originated primarily from the food-insecure Gulf States. Examples of such government-backed investments include the government of Qatar's attempt to secure land in the Tana River Delta and the Saudi government's King Abdullah Initiative. Additionally, sovereign walth funds acting as the investments arms of governments have initiated a number of agreements in Sub-Saharan Africa. Since the population of the Gulf states is set to double from 30 million in 2000 to 60 million in 2030, their reliance on food imports is set to increase from the current level of $60 \%$ of consumption. The director general of the Arab Organisation for Agricultural Development echoed the sentiment of many Gulf leaders in proclaiming, "the whole Arab World needs of cereal, sugar, fodder and other essential foodstuffs could be met by Sudan alone."

\section{Biofuels}

Biofuel production, currently comprising $21 \%$ of total land investments, has played a significant, if at times unclear, role. The use and popularity of biofuels has grown over the past decade, corresponding with rising oil prices and increased environmental awareness. The total area under biofuel crops more than doubled between 2004 and 2008, expanding to 36 million ha by 2008. This rise in popularity culminated in EU Directive 2009/28EC in April 2009, which set 10\% mandatory targets for renewable energy use, primarily biofuels, out of the total consumption of fuel for transport, by 2020. Taken as a whole, the rise in biofuels popularity, while perhaps beneficial for the environment, sparked a chain reaction by making biofuels production a more attractive than food production and drawing land away from food to biofuel production.

The effect of the rise in popularity in biofuels was two-fold: first, demand for land for biofuel production became a primary driver of land sales in Sub-Saharan Africa; second, demand for biofuels production crowded out supply of traditional food crops worldwide. By crowding out food crops and forcing conversion of existing food-producing land to biofuels, biofuels production had a direct impact on the food supply/demand balance and consequently the food price crisis. One researcher from the IFPRI estimated that biofuels had accounted for 30 percent of the increase in weighted average grain prices. 


\section{Criticism}

Large-scale investments in land since 2007 have been scrutinized by civil society organizations, researchers, and other organizations because of issues such as land insecurity, local consultation and compensation for land, displacement of local peoples, employment of local people, the process of negotiations between investors and governments, and the environmental consequences of largescale agriculture. These issues have contributed to critics' characterization of much large-scale investment since 2007 as "land grabbing," irrespective of differences in the types of investments and the ultimate impact that investments have on local populations.

\section{Land insecurity}

One of the major issues is land tenure: In a 2003 study, the World Bank estimated that only between 2 and 10 percent of total land in Africa is formally tenured. Much of the lack of private ownership is due to government ownership of land as a function of national policy, and also because of complicated procedures for registration of land and a perception by communities that customary systems are sufficient.World Bank researchers have found that there existed a strong negative statistical link between land tenure recognition and prospective land acquisitions, with a smaller yet still significant relationship for implemented projects as well. They concluded that "lower recognition of land rights increased a country's attractiveness for land acquisition," implying that companies have actively sought out areas with low land recognition rights for investment.

\section{Local consultation and compensation}

While commonly required by law in many host countries, the consultation process between investors and local populations have been criticized for not adequately informing communities of their rights, negotiating powers, and entitlements within land transactions.

Consultations have been found extremely problematic due to the fact that they oftentimes reach just village chiefs but neglect common villagers and disenfranchised groups. World Bank researchers noted that "a key finding from case studies is that communities were rarely aware of their rights and, even in cases where they were, lacked the ability to interact with investors or to explore ways to use their land more productively." When consultations were even conducted, they often did not produce written agreements and were found to be superficial, glossing over environmental and social issues. In Ghana and elsewhere, chiefs often negotiated directly with investors without the input from other villagers, taking it upon themselves to sell common land or village land on their own.Moreover, investors often had obtained approval for their projects before beginning consultations, and lacked any contractual obligation to carry out promises made to villagers.

There is a knowledge gap between investors and local populations regarding the land acquisition process, the legal enforceability of promises made by investors, and other issues. The inability of villagers to see and study the laws and regulations around land sales severely deteriorates communities' agency in consultations. When consultations do occur with communities, some take place in spans of only two to three months, casting doubt on whether such short time frames can be considered as adequate consultation for such large, wide-reaching, and impactful events.

An additional concern with consultations is that women and underrepresented populations are often left outside during the process. Large-scale projects in Mozambique rarely included women in consultations and never presented official reports and documents for authorization by women. This holds true when women are the primary workers on the land that is to be leased out to companies. Meanwhile, pastoralists and internally displaced people were oftentimes intentionally excluded from negotiations, as investors tried to delegitimize their claims on land. This led to a lack of awareness on the part of these vulnerable groups until lease agreements have already been signed to transfer land. This oversight in consultations further disenfranchises previously overlooked 
communities and worsens power inequities in local villages.

\section{Displacement}

Another criticism of investment in land is the potential for large-scale displacement and of local peoples without adequate compensation, in either land or money. These displacements often result in resettlement in marginal lands, loss of livelihoods especially in the case of pastoralists, genderspecific erosion of social networks. Villagers were most often compensated as according to national guidelines for loss of land, loss of improvements over time on the land, and sometimes future harvests.However, compensation guidelines vary significantly between countries and depending on the types of projects undertaken. One study by the IIED concluded that guidelines for compensation given to displaced villagers in Ethiopia and Ghana was insufficient to restore livelihoods lost through dislocation.

There are a number of issues with the process of relocating locals to other areas where land is less fertile. In the process of relocation, often changed or lost are historical methods of farming, existing social ties, sources of income, and livelihoods. This holds drastic impacts especially in the case of women, who rely greatly upon such informal relationships.

\section{Employment}

When not displaced, the conversion of local farmers into laborers holds numerous negative consequences for local populations. Most deals are based on the eventual formation of plantationstyle farming, whereupon the investing company will own the land and employ locals as laborers in large-scale agricultural plots. The number of jobs created varies greatly dependent on commodity type and style of farming planned. In spite of this volatility, guarantees of job creation are rarely, if ever, addressed in contracts. This fact, combined with the intrinsic incentives towards mechanization in plantation-style production, can lead to much lower employment than originally planned for. When employed, locals are often paid little: In investments by Karuturi Global in Ethiopia, workers are paid on average under $\$ 2$ a day, with a minimum wage of 8 birr, or $\$ 0.48$, per day, both of which are under the World Bank poverty limit of $\$ 2$ per day.

\section{Government negotiations}

In addition to the lack of coordination between ministries, there is a wide knowledge gap between government-level offices and investors, leading to a rushed and superficial investment review. Many government agencies initially overwhelmed by the deluge of investment proposals failed to properly screen out non-viable proposals.Due to the knowledge gaps between government agencies and investors, "in most countries it is implicitly presumed that investors will have the right incentive and be the best qualified to assess economic viability," leading to a lack of reporting requirements or monitoring arrangements, key information on land uses and value of the investment, and checks on economic viability. The Sudanese government has been noted as having paid minimal attention to existing land rights and neglecting to conduct any economic analysis on potential projects. In addition, many countries, including Cambodia, Congo, Sudan, and Ghana, have neglected to catalog and file even general geographical descriptions of land allocation boundaries.

One addition to many contracts between governments and investors is a Stabilisation Clause, which insulates investors from the effect of changed governmental regulations. Such clauses severely restrict the government's ability to change any regulations that would have a negative economic impact on the investment. While advantageous for businesses, these stabilization clauses would severely hinder the ability of governments to address possible social and/or environmental concerns that become apparent after the beginning of the project. 


\section{Environmental impact}

Land investment has been criticized for its implicit endorsement of large-scale industrial agriculture, which relies heavily on costly machinery, fertilizers, pesticides, and other inputs, over smallholder agriculture. As foreign investors begin to develop the land, they will, for the most part, start a shift towards large-scale infrastructure to improve upon existing "unproductive" agricultural methods. The threat of the conversion of much of Africa's land to such large-scale agriculture has provoked a severe pushback from many civil society organizations such as GRAIN, La Via Campesina, and other lobbyists for small-scale agriculture.

Foreign investors, through large-scale agriculture, increase the effectiveness of underused resources of land, labor, and water, while further providing additional market connections, large-scale infrastructure development, and provision of seeds, fertilizers, and technology. Proposed increases in production quantity, as touted by investors and hosts, are exemplified by Ethiopia's Abera Deressa, who claims that "foreign investors should help boost agricultural output by as much as $40 \%$ " throughout Ethiopia. However, large-scale mechanized agricultural production often entails the use of fertilizers and intensive farming techniques that have been criticized by numerous civil society actors as extremely ecologically detrimental and environmentally harmful over the long run. Over time, such intensive farming threatens to degrade the quality of topsoil and damage local waterways and ecosystems. As such, civil society actors have widely accused land investors for promoting "not agricultural development, much less rural development, but simply agribusiness development."This trend towards large-scale agriculture that overrides local knowledge and sustainable local farming runs directly counter to the recent IAASTD report, backed by the FAO, UNDP, World Bank, and others, that to increase food security over the long term, sustainable peasant agriculture must be encouraged and supported.

\section{Neocolonialism}

Foreign investment in land has been criticized by many civil society actors and individuals as a new realization of neocolonialism, signifying a renewed economic imperialism of developed over developing nations.Critics have pointed to the acquisitions of large tracts of land for economic profit, with little perceived benefit for local populations or target nations as a whole, as a renewal of the economically exploitative practices of the colonial period.

\section{Laws and Regulations Concerning Reporting of Foreign Investment in Land}

A 2013 report found no available literature giving recommendations for how the UK could change its laws and regulations to require UK companies investing in land in developing countries to report relevant data.

The researcher looks at a literature review by Global Wintess, the Oakland Institute, and the International Land Coalition from 2012 which states that there is little sustained focus on the extraterritorial obligations of states over overseas business enterprises.

The researcher found most available literature and policy on transparency in land investment focusing on:

- Facilitating community engagement in planning decisions and enhancing community rights

- Upgrading obligations/capacities of host governments to improve regulation of foreignfunded land deals.

- Developing international frameworks to improve transparency in land deals.

He found this focus was confirmed by a range of other documents reviewing address international efforts to promote responsible investment in agriculture and recommended the International Working Group paper and Smaller \& Mann. The researcher mentions a report by the Interntional Institute for Sustainable Development stating a 'significant lack of concrete and verifiable' 
empirically-based policy and legal work on the issue of foreign investment in agricultural land

The researcher saw Smaller and Mann note that in many host states like the UK 'there is either no, or insufficient or unclear domestic law concerning land rights, water rights, pollution controls for intensive agriculture, human health, worker protection and so on.

The researcher did find that international law framework provides hard rights for foreign investors with two primary sources of international law relating to this issue: international contracts, which are commercial in nature; and international treaty law on investment, with both bodies acting on a commercial perspective and focusing on economic interests of foreign investors, rather than social or environmental dimensions.

He discussed the UN's Guiding Principles for Business and Human Rights which address the extraterritorial obligations of states over overseas business enterprises and finds the principles do not provide any detailed discussion of the UK case, or of timeframes and costs

\section{References:}

- Terminski B., Development-Induced Displacement and Resettlement: Causes, Consequences, and Socio-Legal Context, Ibidem Press, Stuttgart, 2015.

- Grajales J., „Land grabbing, legal contention and institutional change in Colombia”, Journal of Peasants Studies, 2006. 